\title{
BaTonga Culture: A Rich Heritage
}

\author{
Umali Saidi \\ Midlands State University, Zimbabwe \\ saeedu2010@gmail.com, saidiu@msu.ac.zw
}

\begin{abstract}
There is a tendency in which so called 'developed' ethnic groups, given their economic, political and social advantage placing them at the 'center', are the chanters of development even for the groups considered to be at the periphery. Ironically, in heritage terms, so called marginalized groups have had much of their heritage less contaminated by forces of modernity as has been the case with much of the BaTonga culture. This article explores the BaTonga culture and heritage as the Zimbabwean aquaculture from which its consumption, preservation and use can benefit other ethical groups in the country. Using results from studies by Saidi $(2016 a)$ as well as complementary studies by Mashingaidze (2013) and Ndlovu (2013), this article establishes the richness of BaTonga culture which subsequently feeds the rich Zimbabwe multicultural heritage. The article argues that heritage utilization reflects the active participation of its owners pointing to the character of the culture making heritage management a priority for any African country seeking its true identity. Further, the article argues that a rich heritage is a shared commodity regardless of ethnic-specific dichotomies in oriented communities like Zimbabwe. Given this basis, the article shows that public spaces, media and the education curriculum are expected to uphold and incorporate all aspects of heritage such as BaTonga cultural realities in order to foster tolerance, acceptance as well as visibility and ultimately cultural and economic development of all ethnic groups in nation building.
\end{abstract}

Key Words: heritage, culture, ethnic, BaTonga, development, aquaculture

\section{Introduction}

$\mathrm{T}$ here is a tendency in which so called 'developed' ethnic groups, given their seemingly obvious positions at the center, are always considered the chanters of developments even for the groups perceived to be at the periphery. Akudinobi (2001) bemoaned African realities of having to struggle for 'survival' than 'development'. He sums up the African condition as 'trapped in a state of stasis' in what many have come to describe as 'a culture of survival - not one of development.' It is no surprise therefore that the view that planners of development strategies in Africa have exclusively focused on social, political and economic issues as authored or experimented by so called 'dominant' groups. Such an attitude has seen marginalized groups such as the BaTonga, 
Nambya, Kalanga and Doma to mention but a few in the country, having to be stretched, at times to breaking points, to adhere to development initiatives as experimented or implemented within and for the dominant ethnic groups. Ironically, in heritage terms, so called marginalized groups have much of their heritage less contaminated by forces of modernity as has been the case with much of the Zimbabwean BaTonga culture.

In this article, I explore some of the Zimbabwean BaTonga cultural assets, showing the richness of the same against the backdrop of Zimbabwean heritage. Further, I demonstrate how the BaTonga in Zimbabwe can be viewed as the custodians of the Zimbabwean aquaculture given their cultural, historical and geographical proximity to the mighty Zambezi river to the north of the country. I also argue that the Zimbabwe BaTonga culture has benefited other ethnic groups in the country (and even beyond). Using results from studies by Saidi (2016a) as well as complementary studies by Mashingaidze (2013) and Ndlovu (2013), the study establishes the richness of BaTonga culture which subsequently feeds the rich Zimbabwe multicultural heritage. The article thus ends by arguing that heritage utilization, above other things, reflects the active participation of its owners, in this case the BaTonga, at the same time pointing to the character of the culture that makes heritage management a priority for any African country seeking its true identity.

\section{The BaTonga people of Zimbabwe}

BaTonga occupy the greatest geographical space along the Zambezi in Zimbabwe as compared to other ethnic groups in the country. However, there are also Tonga people of Zambia (Colson 1971, Panos 2005, McGregor 2009, Hughes 2010). Loewinger (1979 p.356) identifies as well the Tonga of Malawi whom he says are,

....sometimes described as the Switzerland of Malawi, lies in one of the pockets of broken lowland, marked and surrounded by mountains, on the western shore of the northern half of Lake Malawi. It is encircled by mountain ranges in the north, west and south....

Cliggett, Colson, Hay, Scudder and Unruh (2007 p.19) speak of the Tonga, both in Zambia as the 'Gwembe Tonga people' who, 'have learned to respond to uncertainty by expecting the worst of the government, of other organizations and groups, and of the environment', a similar characteristic that also applies to the Tonga of Zimbabwe. While the two (Zimbabwe and Zambia) share common histories and ancestry; Loewinger (1979) does not explain any link between the Malawian Tonga with those in Zambia and Zimbabwe. We can only assume here that there must be some degree of links given the geo-aqua character as the Zambian and Zimbabwean are found close to the Zambezi river with the Malawian also occupying a considerable geo-area along Lake Malawi. Further, Loewinger (1979) noted that the Malawian Tonga follow matrilineal lines of relations which is also a similar traditional case with the Zimbabwean Tonga. However, 
the Tonga in Zimbabwe have over the years become 'different' from their kin in Zambia (and possibly in Malawi) by virtue of their neglect in historical and cultural spheres.

Nchito (2010) studying the migratory patterns of the Tonga people speaks of them as having a 'weak tribal structure' (Nchito, 2010 p.92) which could not withstand the modern pressure of the colonial settlers. Nchito (2010) closely looks at the Tonga of Zambia, although revealing notions observable in the Tonga people in Zimbabwe. In Zimbabwe, the BaTonga now occupy areas around Binga and surrounding remote areas, parts of Gokwe and Kariba; of these geographical locations, Binga is the hub of the BaTonga people in Zimbabwe (Monda, 2011).

Gambahaya and Muhwati's (2010) study of the oral literature of the Tonga people reveals how the BaTonga people protest and write their past as well as experiences through their oral literature and themes like dislocation from the Zambezi River and how the river was central in defining the livelihood of the Tonga people. Apart from Gambahaya and Muhwati (2010 p.322) deliberately placing the Tonga against the European coloniser, they are not explicit on whether they are studying the Zimbabwean BaTonga or Zambian BaTonga as identifying the Tonga calls for specificity as to whether one is referring to the Zimbabwean or Zambian BaTonga. Before colonialism and the demarcation of the African continent, the mighty Zambezi river was not even a frontier as the BaTonga were one ethnic group moving back and forth on both sides (Zimbabwe and Zambia) of the mighty river.

Much of the studies identifying the Zimbabwean BaTonga reflect that they are a marginalised group in the country as compared to the Zambian BaTonga who appear to be a dominant group, especially in the Southern Part of Zambia (Kodamaya, 1995). Dixon-Fyle (1983 p.423) even says of the Zambian Tonga that they are 'resident in the greater part of Southern Zambia.' Studies by Colson (1971), Hughes (2010), MacGregor (2009), Cliggett et al (2007) and even Panos (2005) are clear in that they are centred on the Zambian BaTonga where in splintered circumstances the Zimbabwean BaTonga are referred to.

Scholars like Posner (2003) reflect that at independence in 1964, linguistically, Tonga in Zambia was among the four dominant languages with Bemba, Nyanja and Lozi being the other three. In Zimbabwe, it had to take the 2013 new constitution to recognise Tonga language as one of the sixteen officially recognised languages almost twenty-three years after independence. Posner goes on to state that by 1990 an estimated $79 \%$ of the Zambians used one of these four languages as either their first or second languages of communication. This colonial administrative niche explains how contemporary dominant and subsequently marginalised ethnic groups came to be in Africa. Hence, the Tonga in Zimbabwe have been viewed as a marginalised ethnic group with Shona and Ndebele being the dominant ones. Posner notes that, 
...colonial administrative practices were responsible for creating not just groups, but also the landscape of ethnic cleavages that structure contemporary political and social life. The ethnic landscape is important because the dynamics of ethnic competition and conflict stem not from the existence of ethnic groups but from the geometry of their relative sizes and geographic location...(Posner, 2003 p.127).

The marginalisation of the Zimbabwean BaTonga is quite visible and has been economic, social, political and even cultural. Dzingirayi (2003) for instance has demonstrated how the Communal Management Programme for Indigenous Resources (CAMPFIRE), a colonial wildlife policy, spearheaded by the Zimbabwean government, disfranchised and marginalised the Tonga economically and socially. Hence, as a community whose history is marred with geographical dislocation, betrayals and forgotten by the state (Dzingirayi 2003, Gambahaya and Muhwati, 2010), the BaTonga continued survival in Zimbabwe, while confined in the deep remote valley 'a factor which partly contributes to their political invisibility' (Dzingirayi, 2003 p.248) as well as cultural invisibility; recognition, lies largely in studies of this nature aimed at showing that the Zimbabwean BaTonga (henceforth BaTonga) rich heritage is one of a kind in the country and stands out quite visible from which BaTonga continue to negotiate for cultural space and relevancy.

\section{BaTonga and the hydroelectric project}

The construction of the Kariba Dam was initiated by the Federal Rhodesia and Nyasaland government and was funded by the World Bank in the late 1950s (Hughes, 2010, MacGregor 2009, Mashingaidze 2013, Saidi 2013) to bring development, ironically, to the interior and power Western owned industries as well as light up their suburbs. Mashingaidze (2013) submits that the BaTonga did not benefit from the hydroelectric project with its subsequent resources, Zambezi waters as well as safaris along the shores hence his conclusion that displacement and BaTonga's neglect from accessing the man made as well as natural resources along the Zambezi valley was tantamount to BaTonga's stumbling of their rights first by the colonial government and later by the independent government.

It should be noted that the 'development' niche during the 1950s was also a deliberate move by the West to prove how their degree of 'civilization' equipped them to 'tame' the mighty Kasamba besi symbolizing, as evidenced too by their discourses of the time (Hughes 2010), that, there was nothing mightier within the African cosmos their 'civilization' would not tame. Hence, the African was expected to benefit from their explorations and development undertakings. We thus learn today that the BaTonga heritage was not in fact tamed as evidenced by its richness as has been proved by various studies for instance, Hughes (2010) and Saidi (2016a). 
Indeed, the BaTonga people, whose ancestral lands were the Zambezi Valley, had to be painfully overshadowed by the imperialist approach to development. The BaTonga were deliberately made invisible not only in their physicality, but in discourses as well as in the history of the Zambezi valley (McGregor 2009, Hughes 2010, Colson 1971). Mashingaidze (2013) narrates how BaTonga were sidelined by the Rhodesian government, deprived of economic, social and cultural resources. To make matters worse, at independence in 1980 'well-connected Ndebele and Shona peoples gradually substituted Europeans as the major beneficiaries in the exploitation of the Zambezi Valley's natural wealth' (Mashingaidze, 2013 p.382).

Not only was the river they relied on for sustenance renamed from Kasamba besi to Zambezi but as rightly noted by Ncube (2004), Saidi (2013), Saidi (2016a, and 2016b), the BaTonga were even relocated to the arid, in some cases tsestse infested areas far removed from their once fertile lands for instance in parts of Gokwe, Binga and surrounding areas (Saidi 2016a). Mashingaidze (2013 p.382) notes that the lands were identified by the BaTonga as 'lusaka', that is, 'busy, waterless and tsetse infested' lands. Wildlife was also affected by the floods in 1957 and 1958. Up to 7000 animals as documented by Hughes (2010), were relocated under the biblical banner, 'Operation Noah' creating game parks such as Matusadonha and Chete Safari Areas. A statue still stands today in Kariba in honour of Operation Noah and none was erected to honour the BaTonga.

The BaTonga people lost their ancestral lands and were relocated to the arid, tsetse infested remote areas far removed from their ancestral lands. Their terrain was renamed, that is, reconfigured and the BaTonga existence along the Zambezi river was overshadowed by western imperial maneuvers deleting along the way BaTonga presence historically and socially. Their livelihood was centered on the Zambezi River; and being an agrarian community, the BaTonga used the fertile lands to grow crops all year round and the river provided fish for their diet hence the use of mazubo -the locally made fishing nets. The mighty river was also used for religious purposes where special places along the river were marked as special places for worship, the now Victoria Falls is a typical example. David Livingstone rode on the knowledge of the BaTonga is his erroneous 'discovery' of Mosia oa Tunya, which he renamed after the Queen Victoria of England to Victoria Falls.

The Operation Noah animal rescue project was the major demonstration of how the BaTonga mattered less as compared to the animals that were affected by the rising Kariba waters. This is not to imply that priority should have been given to people over wildlife, but both mattered as they were equally affected by the hydro-electric power project. While the project set aside $£ 4$ million for resettlement of the BaTonga, a much larger sum was raised via international sources that were concerned about the plight of wild animals (Magadza 2006). Magadza (2006 p. 276) observed that "compared to the funds allocated for 'African resettlement', the relative expenditures were about $£ 968$ per animal versus $£ 50$ per person”. 
Even their historical role in the making of the Kariba, itself renamed from Kariva (a place where the Nyaminyami resided), the very spot where the dam wall was constructed, is quasi-muted. Narratives alluding to the BaTonga elders having intervened (Hughes 2010); appeasement of the Nyaminyami - the BaTonga river spirit (Saidi 2016a), destructions on some parts of the dam wall as well as workers losing lives have little significance to the Zimbabwean community (Saidi 2016a). The BaTonga intervention saw the completion of the dam wall at the height of its construction. Sadly, the narratives do not have a better place in contemporary discourses as something that the country and its people are expected to cherish. After all, the country has benefited immensely from then to present on this intervention which is also loaded with cultural, spiritual and pragmatic relevance.

BaTonga intervened through their elders during the construction of the Kariba dam to foresee its completion. BaTonga activism, which Mashingaidze (2013) discusses at length, by the young generation BaTonga intellectuals in the 1990s reclaims their place and new forms of compensation their ancestors and parents did not receive in the 1950s. Regardless of the neglect the Rhodesian government had towards the BaTonga when they relocated the indigenous people to the unfertile arid areas to pave way for the project, the BaTonga contributed positively to the project, although the narratives have sadly been ignored in national discourses.

The attitudes hence demonstrate how realities around the project defined BaTonga marginalization and domination first by the colonial government and Europeans alike. The definition set up by the Europeans was later assumed by dominant ethnic groups such as the Ndebele and Shona in post independent Zimbabwe.

Even in matters of addressing the BaTonga, terms such as 'minority', 'poor', 'primitive' themselves denigrating, have been used in an effort to identify or describe the BaTonga as an ethnic group. For instance, Mashingaidze (2013) uses the term 'minority' eleven times in his twenty-four-paged study published in an international journal titled 'International Journal on Minority and Group Rights.' There is no effort whatsoever or consciousness to drop the use of the term which has helped in the creation of marginalizing discourses in the country. It goes without saying that even the references made and used by Mashingaidze (2013) and even Ncube (2004) deliberately make use of the same term thus clearly revealing the 'domination' heritage in expressive terminology and discourses in general. And BaTonga have rejected the use of such terms to identify them as an ethnic group (Saidi, 2016a). One wonders if the Europeans in Zimbabwe were not a 'minority' group however with political and economic power to dominate the majority of the Africans. This attitude has created the same systems of viewing the BaTonga and any such marginalized ethnic group along either population size or mostly economic and political power. 
The brief historical reality above reveals the basis on which continued attitudes of denigration often exerted on marginalized groups in our communities are founded on. While the BaTonga had to make do with identity recreations - their territorial space had been renamed to Zambezi, they had been physically relocated leaving their ancestral graves buried in the floods and were thus disadvantaged from accessing and using social, economic and cultural resources for their respective development as an ethnic group with a right to claim in Zimbabwe.

Against the above, I thus discuss below the BaTonga, the Zambezi valley with its unique aquaculture and how it reveals a very rich BaTong dominated heritage which has a special place in Zimbabwe. Further, I note how the BaTonga proudly consume and express their culture hence appreciating the efforts they have put in place to preserve not only their heritage but the Zimbabwean heritage. This is part of the cultural and historical foundation on which the BaTonga activists, (Basilwizi, Binga Development Association, Binga Catholic Commission for Justice and Peace noted by Mashingaidze, 2013) based their activism as well as the successes Ndlovu (2013) observes for the BaTonga in comparison to other marginalized groups like the Nambya, Kalanga and Venda in the country.

\section{The Zambezi heritage-aquaculture}

It has been noted in the sections above that the negative tendency of the economically and politically advantaged 'dominant' groups have towards so called marginalized groups is made to appear as if there is nothing these 'dominant' groups can learn from the groups such as the BaTonga. I proceed to submit that the Zambezi valley has become a 'tourist' as well as a heritage terrain mostly because of the aquaculture as well as the flora and fauna housed in areas fencing off the valley. Below are maps showing the geographical areas under discussion from the Zimbabwean side. 


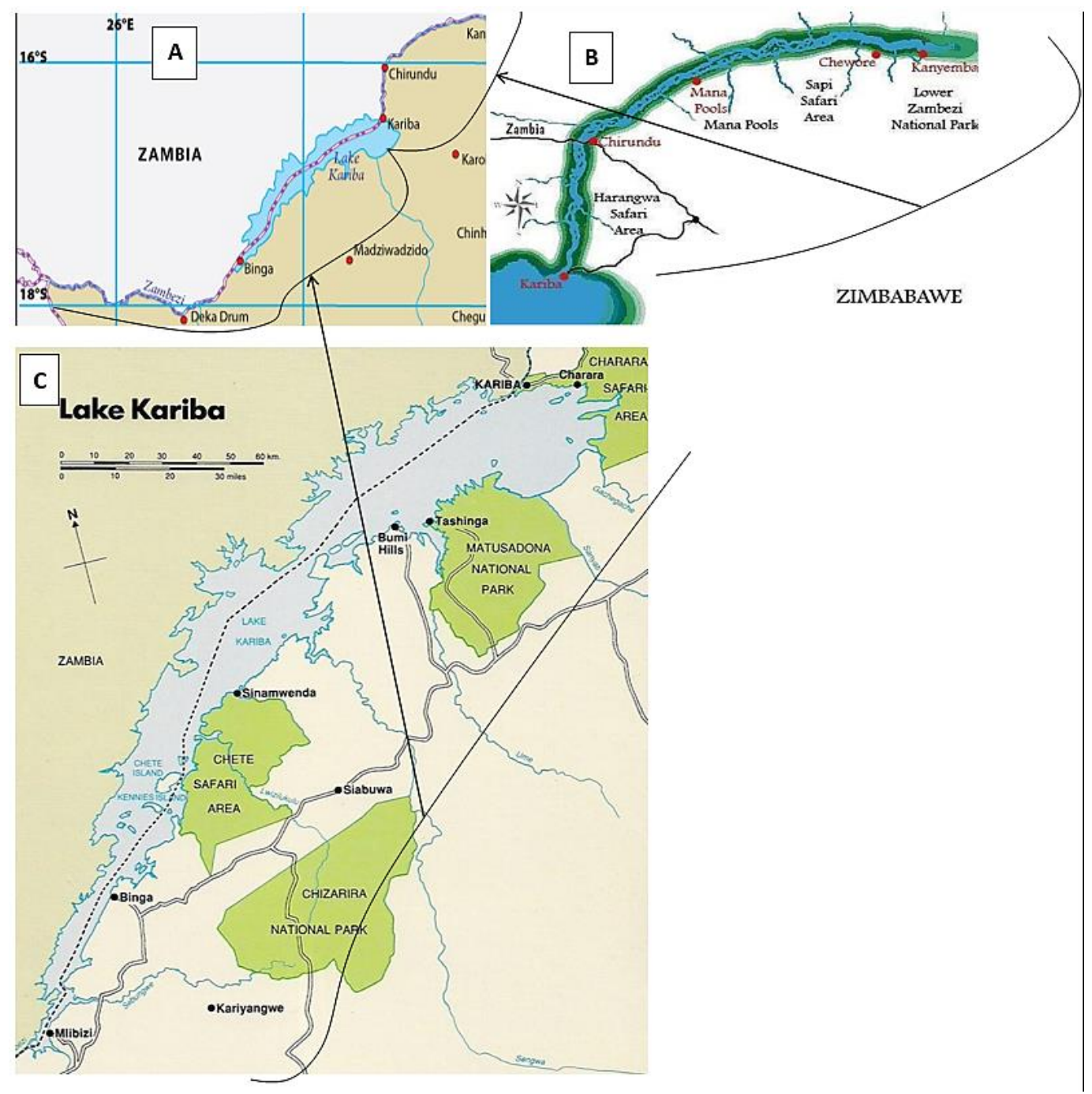

It is evident from the above maps that the national parks and Safari areas promoted Safari businesses from Victoria Falls, through Kariba down to the lower Zambezi section. Subsequently, hotels and lodges were also built (Hughes 2010). Safari businesses as well as the various tourist centers dotted along the Zambezi shores; hotels and lodges have all become and made the Zambezi valley a recreational terrain to which local and international visitors take time to visit. As such, the valley and the Zambezi shores has provided over the years business opportunities as well as employment opportunities. For the BaTonga, sadly, the employment was to work as gardeners or cooks in European owned businesses (Hughes 2010) and after independence, locals (powerful politicians from other ethnic groups) took over or created similar businesses and employed the BaTonga the same way the Europeans had done. 
Indeed, the BaTonga did adjust and identified with new realities and had to seek employment as hunting, fishing for their subsistence as well as farming activities were no longer activities at their disposal. The new laws criminalized hunting and fishing expeditions (Hughes 2010) and these were left to be done for commercial purposes by huge companies. In Binga, BaTonga elders had to lobby the government to be allowed access to fishing (Mashingaidze 2013) from which cooperatives were created in order for the BaTonga to also venture into fishing for commercial purposes.

Employment opportunities were also presented to other people from various parts of the country. For instance, Rainos Tawonameso a sculptor relocated to Kariba from Bikita and became the famous author of the wooden Nyaminyami Walking Stick (Saidi 2016a). Today, various versions of the sculpture are produced by various artists from various backgrounds in Kariba and surrounding areas and hence making a living out of them. At independence, some once European owned businesses were taken over by Ndebele or Shona politically connected and powerful individuals leaving the BaTonga in the same odd jobs. The newly established fishing cooperatives were also in some cases hijacked and taken over by the Shona and Ndebele powerful groups.

The BaTonga, it should be noted, for them the mighty Zambezi River is in fact Kasamba besi, meaning 'those who know the river can bath in it'. It was the Europeans who renamed Kasamba besi to Zambezi. The meaning behind Kasamba besi is loaded with wisdom of great depth as the crocodile infested river requires knowledge to navigate, knowledge to cross from the Zimbabwean side to the Zambian side; knowledge of pools and fishing points from which they would maximize their social, cultural and economic abilities in fishing for their diet. The mighty river was also used for religious purposes for instance in ceremonies like rainmaking ceremonies. Today, hot springs are found in Binga and these were sacred places.

Apart from exercising and utilizing their knowledge of the river, the BaTonga, even today, live side by side with game, which they hunted. Elephant tusks were used to mark ancestral graves for instance before the practice vanished with the coming of Portuguese trade in ivory. The buntibe drum was made using the skin of the elephant. A drummer at Simchembo village (Gokwe), pointed out that skin from the elephant ear was used traditionally to make the membrane of the drum. Their homes were storied and well ventilated (and there is still evidence of the same today in most remote parts of Binga) given the humid conditions of the valley.

Given the lack of attention on the BaTonga and interest even in the lusaka areas they came to assume as their new home, BaTonga culture and values have remained rather less contaminated by forces of modernity. Apart from government interventions on safeguarding wildlife as well as promoting programmes like the CAMPFIRE programme (Dzingirayi, 2003) which to some extent put a stop to hunting and fishing expeditions by the BaTonga as their socio-cultural practice, the BaTonga have been able to consume their culture and express it with pride. While recognition of their language to be used in 
schools and media has been late in coming as well as its recognition by the new 2013 Zimbabwe constitution, we draw lessons from a people who, according to Saidi (2016a), resolutely have been negotiating for space peacefully and cultural successes of heritage value have also been recorded which are worth noting.

Vigilance and continued expressiveness of heritage has made the BaTonga a success story in terms of indigenous language usage among other marginalized groups in Zimbabwe. Between the Venda, Kalanga, Chewa, Sotho and Nambya to mention but a few in the country, the BaTonga have been a success story in Zimbabwe (Ndlovu 2013). Ndlovu (2013) noted (having studied the use of Tonga, Kalanga and Venda) that Tonga language compared to Kalanga and Venda has been successful as it has come to be used in the school system within the geographical centers where the BaTonga now reside. Let us not forget that Venda, Sotho, Chewa and even Tonga are either dominant groupings across the Zimbabwean boarders in the region mostly in South Africa, Zambia and Malawi. It follows therefore that in Zimbabwe, BaTonga now rightly make a claim to Zimbabwe than they may have had to stretch out for acceptance across the border in Zambia or Malawi. The BaTonga success story was made possible by compounded efforts the BaTonga, from their 'marginalized' position, did put in place in advocating for their visibility and recognition in the country. For instance, the Binga Museum was established in Binga to house important cultural, historical material and generally the heritage of the BaTonga people in Zimbabwe as such puts them on the heritage and cultural map.

Because the BaTonga are proud consumers of their culture they also boast of the 'Zambezi anthem' sung in Tonga and they continue to express their culture performatively through the buntibe; the elderly women continue to smoke the ncelwa (Saidi 2016a, Saidi 2016b) or women' smoking pipe (van der Merwe, 2005) although of cause the practice is not so observable among the young BaTonga women given contemporary religious as well as modern cultural practices. The buntibe (drum and traditional performance) continues to sound and be performed during various BaTonga gatherings or any national festivals where they are called in to actively participate. Their language is now being recognized by the new constitution among the fifteen other indigenous languages in the country. This points towards to how a 'small' populated ethnic group from the so-called periphery has contributed so much in terms of character as well as culture to the generality of the heritage of Zimbabwe.

It can be argued that the vibrancy of tourism along the Zambezi valley is benchmarked on the culture and heritage of BaTonga as compared to any other local groups. As is the case with European vs African, the local heritage however is overshadowed by colonial legacies and imprints. This does not 'delete' BaTonga presence as the Eurocentric discourses (Hughes 2010) tried to do. Culture-tourists who visit Kariba, Victoria Falls and even Binga readily consume and interact with BaTonga heritage in terms of the language, artefacts such as the ncelwa, buntibe drums, songs and dance; game as well as the effigies of game, three legged doors, BaTonga stools or chairs, Nyaminyami walking 
stick and narratives that involve the BaTonga. This is what they carry as Zimbabwean heritage back to their countries of origin.

In an effort to preserve their unique culture and history, the BaTonga at the dawn of the $21^{\text {st }}$ century came with a tangible defined cultural heritage space in the form of the BaTonga Museum as has already been pointed out above. Today in Binga, stands a civil BaTonga space where the BaTonga not only re-write their history but have a tangible civil space that houses their unique heritage. Catapulted by the fact that the museum is located within the Zambezi valley, it makes interpretations and valuing of the heritage more meaningful as compared to preservation for instance of material heritage in the national civil spaces far removed from the owners of the same. Is this not a replica of the Great Zimbabwe Museum located right at the heart of the Great Zimbabwe Monuments? While the Great Zimbabwe Museum houses heritage and history of the Great Zimbabwe, the BaTonga Museum also houses the history and heritage of the BaTonga people making it possible for the BaTonga to be custodians of their own heritage and history as well as active tellers of that history and heritage.

There are other ethnic groups that have been 'engulfed' by the Shona or Ndebele over the years such as the Kalanga or Venda in Beitbridge (Ndlovu 2013) or the Chewa who migrated to Zimbabwe from Malawi. For example, among the Shona, specific ethnic identities may be very difficult to observe and the same may apply to the heritage expressed materially or otherwise. The common approach has been, for instance, to observe expressions or heritage as belonging to the Shona when some degree of specificity may be required. This development can be assumed to be detrimental especially in as far as heritage and cultural sensitivity is concerned as the aspects of a specific group are lost or over-shadowed in the national civic spaces located in Harare and large centers of the country. This of course can be seen as one of Clement Doke's errors he made for the Shona people in 1931 where five dialects were linguistically staffed, and so the speakers were staffed too under one broad linguistic identity.

To identify that which is Manyika or Korekore appears to be challenging in modern day Zimbabwe. Hence, if the Korekore or Manyika are to come up with community museums like what the BaTonga have done, it will help preserve their specific ethnoheritage even if it may have something in common with that of the Shona in general. Studies by McGregor (2009), Colson (1971), Hughes (2010), Ncube (2004), Mashingaidze (2013) and even Saidi (2013,2016a) make us conclude that the BaTonga are the country's custodians of part of the Zimbabwean heritage and history as found in the Zambezi valley.

Matters of heritage in contemporary times reveal that a rich heritage is in fact a shared commodity regardless of ethnic-specific dichotomies in oriented communities like Zimbabwe. To this end, public spaces, the media and the education curriculum are expected to uphold and incorporate all aspects of heritage such as the BaTonga cultural 
realities in order to foster tolerance, inclusivity as well as visibility; and ultimately cultural and economic development of all ethnic groups in nation building.

\section{Final thought}

One point worth noting is the painful journey the BaTonga have travelled in history over the years. Some western scholars like Lessing (1982) at the dawn of Zimbabwean independence had the courage to say 'Do not go to Binga, it will break your heart.' This was of cause the feeling of the pre-and post-independent era of the time, to which Binga, and subsequently the BaTonga, in terms of 'development' appeared to have been lagging behind in terms of infrastructure, schools and so on as compared to successes celebrated at the time in some areas in the country. But what can be celebrated about the BaTonga against all odds is the heritage and humanity in them, obviously accredited to the nature of their culture.

There have not been militant calls for recognition by the BaTonga (Saidi 2016a, Saidi 2016b) as has been the case with marginalized groups in a possible similar situation across the African continent where internal militia groupings are created, funded and even armed by the West to demand a place within the polity using the barrel of the gun. Results have thus been obvious in such countries such as DRC and Rwanda. Bloodshed, loss of humanism and migration have been the reality from which the core of such groups have been destroyed making it difficult for the 'center' to hold. Hence, the BaTonga could be said to have used their culture which is characterized by ubuntuism as evidenced by how the government has also come to recognize their efforts in various ways. When Zimbabweans are identified as a hospitable and peaceful people, these are some of the contributing factors and ethnic diversity is not seen as a factor to divide the people but to unite them.

There are various important aspects that we can learn from the BaTonga which can be emulated and be used across the country. It is no secret that poverty to some extent has been used to characterize the BaTonga not mentioning some misplaced submissions of the BaTonga as 'backward' as has become an approach especially in viewing the Doma people (Mazara, 2015) who are also inhabitants of the Zambezi basin. Humility, constant internal organization, vision, and constant desires by the BaTonga to remain steadfast on their culture and being has seen even the outside world coming to assist in the realization of the vision the people have. For instance, the Binga Museum is founded on the principled desire to reflect that which is BaTonga. Within the same place a library has been built as well as a crafts center. What we read in this organization is, for preservation and learning BaTonga culture and heritage, the Museum offers such and when one wants to read about the BaTonga, then the library offers such services and the crafts center is there for one to buy mementoes (Saidi 2016a) from the BaTonga heritage and culture. Such an organization requires the local people to be culture and heritage sensitive not mentioning the sustainable development niche around the idea. 
A number of ethnic groups have seen the local people regrettably abandoning their culture for other Western traits. This alone offers no possibility for investment in one's culture. As such lessons, can be drawn from the men and women from Binga and surrounding areas who found themselves far away from their ancestral lands and have been able to invest in their own culture and thus seeing the cultural and historical center being constructed in Binga. Part of the drive is provided by Mashingaidze (2013 pp.38687) who says

A generational cohort of young and educated Tonga people born after displacement to the uplands spearheaded these civil society anchored demands. Their articulations of the Tonga's rights to socio-economic empowerment differed from those of the nationalist leaders like Muntanga and Munkombwe who dominated the electoral politics of Binga in the first decade after independence. These elderly nationalist leaders aligned their claims for Tonga empowerment to the new post-colonial consciousness of nationhood. Central to this consciousness were three elements: centralised and socialist oriented development planning; one-party-state politics; and the empowerment of an undifferentiated category of blacks that had endured socio-economic exclusion under the colonial dispensation. This hegemonic consciousness of nationhood disregarded local sentiments and ethnic interests, a phenomenon that was common to most post-colonial African countries in the immediate aftermath of their independence... The young Tonga activists of the 1990s and 2000 s challenged this "frowning upon" of the expression of sectional community and ethnic interests. They appropriated and deployed emerging global ideas of heritage and identity as well as the liberal parlance of rights, development and citizenship in framing their struggles for the improvement of their people's livelihoods.

What we hence appreciate from the young BaTonga shall thus ever remain a cultural legacy unique as well as of heritage significance to come out of and among the considered poverty stricken and 'backward' people from which other groups in the country need to emulate and support.

Saidi (2016a, 2016b) has already shown how sophisticated the ncelwa (women smoking pipe) signifies the ingenuity of the BaTonga women who ironically are part of what the society consider as 'marginalized.' With the STEM revolution underway in the country, we hope the ncelwa may further be studied and ideas as well as technologies invented to benefit not only the BaTonga but the country at large. It is also hoped that with the new efforts in curriculum development for the education system, especially the call by the respective Ministry to have cultural centers or villages constructed in schools such as the million-dollar state of the art Regina Mundi High School (Gweru) cultural center.

Much of the tooling of such centers would then involve collecting artefacts such as the ncelwa (women smoking pipe), BaTonga wooden doors, chairs, buntibe drums, cete (male smoking pipe) and nyeele (whistles made out of goat or antelope horns) among 
others, to be brought into visual cultural dialogues with other artefacts from other ethnic groups such as the rattles, clay pots and so on. If our children are to be exposed to the heritage of the country as represented by actual artefacts, their knowledge of their surroundings will motivate them to appreciate and forever work for their communities as well as tolerate each other. This will be more beneficial as the tourist market has a regrettable tendency to externalize the heritage to which at times the heritage may be misinterpreted or misused as what happened in 2012 when the Nyaminyami Walking Stick appeared in an American blockbuster as a religious tool used in the film to commit murder.

\section{Conclusion}

I have explored some of the Zimbabwean BaTonga cultural assets, showing the richness of the same against the backdrop of Zimbabwean heritage. Further, I have demonstrated how the BaTonga in Zimbabwe are the custodians of the Zimbabwean aquaculture given their cultural, historical and geographical proximity to the mighty Zambezi river to the north of the country. I have also argued that the Zimbabwe BaTonga culture has benefited other ethnic groups in the country although a deliberate push is needed to promote this rich heritage to all schools and exposure in the media in order for the country to draw some lessons from the successes of the BaTonga. Apart from the historical realities of neglect and displacement, I have shown that BaTonga's heritage has remained less contaminated although modernity and Christianity now pose challenges to the upholding of some of the cultural practices such as the smoking of the ncelwa by women. It is therefore hoped that heritage utilization, above other things, reflects the active participation of its owners and make heritage management a priority for any African country seeking its true identity.

\section{References}

Akudinobi, J. (2001). Nationalism, African Cinema and frames of scrutiny Research in African Literatures 32(3), pp.123-142.

Colson, E. (1971) The social consequences of resettlement: the impact of the Kariba resettlement upon the Gwembe Tonga. Manchester University Press: Manchester.

Cliggett, L., Colson, E., Hay, R., Scudder, T. and Unruh, J. (2007) Chronic uncertainty and momentary opportunity: A half century of adaptation among Zambia's Gwembe Tonga, Human Ecology, 35(1), pp.19-31.

Dixon-Fyle, M. (1983) Reflections on economic and social change among the plateau Tonga of Northern Rhodesia, c. 1890-1935 The International Journal of African Historical Studies, 16 (3) pp.423-439. 
Dzingirayi, V. (2003). The Scramble for the African countryside. Development and Change 34(2). Blackwell Publishing, Oxford, pp243-263.

Hughes, D. M. (2010). Whiteness in Zimbabwe: Race, Landscape and the problem of belonging, Palgrave Macmillan: New York.

Hughes, D. M. (2006). Whites and Water: How Euro-Africans Made Nature at Kariba Dam, Journal of Southern African Studies, 32:4, pp.823-838.

Kodamaya, S. (1995) Migration, population growth and ethnic diversity of a village in the central Zambia, Hitotsubashi Journal of Social Studies 27(2), pp.97-111.

Lessing, D. (1982). African Laughter: Four visits to Zimbabwe, HarperCollins: Lomdon.

Loewinger, A. (1979) Labor migration in Southern Africa among the Lakeside Tonga of Malawi Journal of International Affairs, 33(2) pp. 355-359.

Magadza, C. (2006). Kariba Reservoir: Experience and lessons learned. Lakes \& Reservoirs:Research \& Management. Volume 11, Issue 4, p276.

Mashingaidze, T. (2013) Beyond the Kariba Dam induced displacements: The Zimbabwean Tonga's struggles for restitution, 1990s-2000s, International Journal on Minority and Group Rights 20, pp. 381-404.

Mazara, G. (2015) The ostrich people of Zimbabwe The Sunday Mail, 1 November 2015, Available at http://www.sundaymail.co.zw/feature-the-ostrich-people-ofzimbabwe/ Accessed on 20 December 2016.

McGregor, J. (2009). Crossing the Zambezi: The politics of landscape on a Central African frontier Weaver Press: Harare.

Ncube, G. T. (2004). A history of northwestern Zimbabwe, 1850-1960, Mond Books: Kadoma.

Ndlovu, E. (2013). Mother tongue education in official minority languages of Zimbabwe: A language management critique, (Unpublished PhD Thesis), University of Free State: Bloemfontein.

Posner, D. N. (2003). The colonial origins of ethnic cleavages: The case of linguistic divisions in Zambia, Comparative Politics, 35(2), pp. 127-146

Saidi, U. (2016a). Cracking the nonverbal code: Analysing the cultural artefacts of the BaTonga in Zimbabwe, (Unpublished PhD Thesis) Midlands State University: Gweru.

Saidi, U. (2016b). Symbols of social transformation: BaTonga search for cultural relevancy in Zimbabwe, The Dyke: A Journal of the Midlands State University, 2016 Special Edition, MSU, pp.162-179.

Saidi, U. (2013). The past in them: Celebrating BaTonga artefacts and visual cultural communication in Zimbabwe Madirativhange: Journal of African Indigenous 
Umali Saidi

Languages and Literature Vol.1 No. 1, Africa Institute for Culture, Peace, Dialogue and Tolerance Studies pp.59-69.

van der Merwe, N. (2005). Antiquity of the smoking habit in Africa Transactions of the Royal Society of South Africa Vol. 60(2) pp.147-150. 